\title{
BMJ Open Psychological and support interventions to reduce levels of stress, anxiety or depression on women's subsequent pregnancy with a history of miscarriage: an empty systematic review
}

\author{
Indra San Lazaro Campillo, ${ }^{1}$ Sarah Meaney, ${ }^{1,2}$ Karen McNamara, ${ }^{1}$ \\ Keelin O'Donoghue ${ }^{1,3}$
}

To cite: San Lazaro Campillo I, Meaney S, McNamara K, et al. Psychological and support interventions to reduce levels of stress, anxiety or depression on women's subsequent pregnancy with a history of miscarriage: an empty systematic review. BMJ Open 2017;7:e017802. doi:10.1136/ bmjopen-2017-017802

- Prepublication history and additional material for this paper are available online. To view please visit the journal (http:// dx.doi.org/10.1136/bmjopen2017-017802).

Received 17 May 2017 Revised 19 July 2017 Accepted 31 July 2017

\section{CrossMark}

${ }^{1}$ Pregnancy Loss Research Group, Department of Obstetrics and Gynaecology, University College Cork - National University of Ireland, Cork, Ireland

${ }^{2}$ National Perinatal Epidemiology Centre (NPEC), University

College Cork - National

University of Ireland, Cork, Ireland

${ }^{3}$ The Irish Centre for Fetal and Neonatal Translational Research (INFANT), University College Cork - National University of Ireland, Cork, Ireland

Correspondence to Indra San Lazaro Campillo; indra.campillo@ucc.ie

\section{ABSTRACT}

Objective The aim of this systematic review was to assess the effect of interventions to reduce stress in pregnant women with a history of miscarriage.

Design A systematic review of randomised controlled trials (RCTs).

Data source A total of 13 medical, psychological and social electronic databases were searched from January 1995 to April 2016 including PUBMED, CENTRAL, Web of Science and EMBASE

Eligibility criteria This review focused on women in their subsequent pregnancy following miscarriage. All published RCTs which assessed the effect of non-medical interventions such as counselling or support interventions on psychological and mental health outcomes such as stress, anxiety or depression when compared with a control group were included. Stress, anxiety or depression had to be measured at least preintervention and postintervention.

Results This systematic review found no RCT which met our initial inclusion criteria. Of the 4140 titles screened, 17 RCTs were identified. All of them were excluded. One RCT, which implemented a caring-based intervention, included pregnant women in their subsequent pregnancy; however, miscarriage was analysed as a composite variable among other pregnancy losses such as stillbirth and neonatal death. Levels of perceived stress were measured by four RCTs. Different types of non-medical interventions, time of followup and small sample sizes were found.

Conclusion Cohort studies and RCTs in non-pregnant women suggest that support and psychological interventions may improve pregnant women's psychological well-being after miscarriage. This improvement may reduce adverse pregnancy-related outcomes in subsequent pregnancies. However, this review found no RCTs which met our criteria. There is a need for targeted RCTs that can provide reliable and conclusive results to determine effective interventions for this vulnerable group.

\section{INTRODUCTION}

Recent studies have focused on the effect of women's psychological well-being during pregnancy and its effects on the mother and

\section{Strengths and limitations of this study}

- To our knowledge, this is the first attempt to systematically look at the psychological effect of non-pharmacological interventions on pregnant women with a history of miscarriage.

- This systematic review increases the awareness of the 'evidence gap' in this vulnerable group.

- It also highlights the clinical importance of including pregnant women in randomised controlled trials and proposes reasons why different types of pregnancy loss should be investigated separately.

- However, this review was limited by the unexpected result and no further analysis could be completed.

infant. ${ }^{1-3}$ Women are highly reactive to stress in early pregnancy. ${ }^{4}$ Approximately $25 \%$ of women report emotional distress during the antenatal period. ${ }^{5}$ Given the importance of maternal psychological well-being for predicting outcomes, it is necessary to effectively examine appropriate interventions to reduce stress in pregnancy. ${ }^{6}$ Very recently, the UK National Institute for Clinical Excellence called for randomised controlled trials (RCTs) to evaluate interventions aimed at tackling moderate to severe psychological disorders in the pregnant population. ${ }^{6}$

Studies on stress during pregnancy have established that psychological stress might be associated with an increased risk of a number of adverse pregnancy outcomes, such as preterm labour and low birth weight. ${ }^{1}$ 7-9 Change in pregnancy-specific stress between the second and third trimester has been significantly associated with an increased likelihood of preterm deliveries ${ }^{9-11}$ and with implications for fetal development. ${ }^{12} 13$ These outcomes are among the leading causes of infant mortality and health problems which 
may persist not just into childhood but throughout their adult lives. ${ }^{7}$

Miscarriage is one of the most common complications during early pregnancy. ${ }^{14} 15$ It is estimated that miscarriage occurs in $20 \%$ of all clinically recognised pregnancies ${ }^{1617}$ and up to half of all pregnancies. ${ }^{18}$ Experience of miscarriage may alter women's psychological and mental health and well-being. ${ }^{6}{ }^{19}$ Miscarriage has been associated with increased levels of distress, ${ }^{20}{ }^{21}$ anxiety and depression. ${ }^{22-29}$ In some cases, the psychological symptoms of anxiety and depression can persist for up to 1 year after miscarriage ${ }^{2630-33}$ In addition, it is increasingly recognised that the adverse psychological and mental health consequences of previous miscarriage continue after the loss and into subsequent pregnancies. ${ }^{22}{ }^{34} 35$ Some examples of the evidence found in the literature included higher levels of psychological distress,${ }^{36-40}$ pregnancy-specific anxiety $^{3841-44}$ and depressive symptoms. ${ }^{445}$

However, few studies have evaluated the beneficial effect of psychological and supportive care in pregnant women who have had miscarriage and who are in their subsequent pregnancy. In a cohort study, Clifford et al (1997) found that pregnant women who followed a specific antenatal counselling support plan had a significantly higher pregnancy success rate than those who did not participate. ${ }^{46}$ Similar results were found in two other cohort studies carried out with women who experienced recurrent miscarriage, ${ }^{47} 48$ which is defined as three or more consecutive pregnancy losses ${ }^{49}$ These studies indicate the potential importance of providing support for women in a subsequent pregnancy following miscarriage. ${ }^{2150}$ Therefore, the aim of this systematic review was to examine the literature to explore the effect of psychological and support interventions to reduce levels of stress among pregnant women who have a history of miscarriage.

\section{METHODS}

The Cochrane Handbook for Systematic Reviews of Interventions, ${ }^{51}$ the Cochrane Consumers and Communication Review group for data synthesis and analysis ${ }^{52}$ and The Preferred Reporting Items for Systematic Review and Meta-Analysis (PRISMA) guideline ${ }^{53}$ were adhered to for conducting and reporting this systematic review (see online supplementary file 1 ). This systematic review has not been registered in the international prospective register of systematic reviews (PROSPERO) database.

\section{Eligibility criteria}

Criteria for considering studies for this systematic review were:

\section{Type of studies}

All published RCTs, including cluster RCT, were systematically searched in this review. Controlled (non-randomised) clinical trials, prospective and retrospective cohort studies, case-control or nested case control studies, cross-sectional studies, case series and case reports were excluded.

\section{Types of participants}

Women in a subsequent pregnancy with a history of miscarriage. Miscarriage was defined as a spontaneous loss of pregnancy from the time of conception until 24 weeks of gestation. ${ }^{54}$

\section{Types of interventions}

All types of non-pharmacological interventions such as psychological, emotional, information or support group interventions, either alone or in combination with another control intervention; for example, standard care or other type of intervention.

\section{Outcomes}

Trials reporting quantitative outcome data were included. The primary outcome was levels of perceived stress which was defined as 'the feelings or thoughts that an individual has about how much stress they are under at a given point in time or over a given time period, ${ }^{55}$ The secondary outcomes were: (1) levels of cortisol which was measured in saliva, urine, blood or hair; (2) levels of perceived anxiety which was defined as the stable tendency to attend to, experience and report negative emotions such as fears, worries and anxiety across many situations ${ }^{, 55}$ and (3) levels of perceived depression which was defined as a 'depressed or sad mood, diminished interest in activities which used to be pleasurable, weight gain or loss, psychomotor agitation or retardation, fatigue, inappropriate guilt, difficulties concentrating as well as recurrent thoughts of death ${ }^{56}$ Secondary outcomes had to also be measured preintervention and postintervention.

\section{Information sources and search}

A total of 13 medical, psychological and social electronic bibliographic databases were searched: PubMed, Cochrane Library, CENTRAL, EMBASE, Web of Science (Web of Knowledge), Cumulative Index to Nursing and Allied Health Literature (CINAHL), Maternity \& Infant Care Database, Science Direct, Elton B. Stephens Co (EBSCOhost), ProQuest Nursing and Allied Health Source, CLINICAL TRIALS, Journal Storage (JSTOR) and Clinical trials websites. The reference lists of potential studies were also screened to identify other relevant studies. Keywords and Medical Subject Headings (MeSH) were used to identify studies related to miscarriage and stress (see online supplementary file 2). The date of the last search was 2 April 2016. There were no restrictions by study design, setting and country. All studies in English language were included. The literature search was limited by date (from January 1995 to April 2016).

\section{Study selection}

Search results were screened by two reviewers (ISLC, $\mathrm{KM}$ ), first by titles and then by abstracts. Discrepancies were resolved with other reviewers (SM, KOD). Eligibility criteria of all potential studies were assessed using 
the 'Data collection form for intervention reviews: RCTs only from April 2014' (by ISLC) ${ }^{57}$ (see online supplementary file 3 ). Due to the variability in definitions of the condition, studies were included where the following terms appeared in their titles: 'miscarriage', 'pregnancy loss', 'perinatal loss', 'spontaneous abortions', 'early miscarriage' and 'first trimester miscarriage'. They were excluded when the following terms appeared: 'stillbirth', 'recurrent miscarriage', 'fetal death', 'infertility', 'subfertility', 'IFV', 'perinatal death', 'missed abortion', 'induced abortion', 'ectopic pregnancy', 'pregnancy wastage, 'oxidative stress', 'antioxidants' and 'Intimate partner violence'. Recurrent miscarriage was excluded because of the differences in the aetiology, diagnosis and therapy between other types of losses. ${ }^{58} 59$ No study was excluded for not identifying the outcome of interest in either title or abstract. ${ }^{60}$

ENDNOTE X7 was the reference management software used to import, classify and analyse all citations in this systematic review. All citations from each database were automatically imported to ENDNOTE and then saved by electronic database and date of searching. Abstracts were also imported when they were available. Data collection was completed by one reviewer using data extraction forms and a second reviewer (SM) independently checked content. Definitions of the condition were obtained from abstracts or reading full reports of the studies. When miscarriage was analysed as a composite with other adverse pregnancy outcomes such as stillbirth or perinatal death, contact with the authors was made by email to try to obtain subsamples of the full datasets. Data extraction forms by the Cochrane Consumers and Communication Review Group ${ }^{61}$ were used to describe main characteristics, methodology and main results (see online supplementary file 4). A summary of the outcomes and the measurement of each outcome was assessed using the outcome matrix of the 'Outcome Reporting Bias of Trial' $\left(\right.$ ORBIT) ${ }^{60}$ (see online supplementary file 5). Risk of bias was assessed using the "Assessment of Risk of Bias' by the Cochrane Bias Methods Group ${ }^{57}$ (see online supplementary file 6).

\section{RESULTS}

A total of 4140 citations were identified through database searches and 8 were identified through other sources. After duplicates were removed, 3325 citations were identified during the screening process (see figure 1).

A total of 17 RCTs and 2 clinical controlled trials (CCTs) were found in this review. This systematic review found no RCT which met all the inclusion criteria. Of the 17 RCTs, 10 were excluded for a variety of reasons including: no outcome of interest, medical intervention instead of non-medical interventions or pregnancy loss defined as a loss later than 24 weeks (table 1). Even though a number of studies $(n=7)$ carried out non-pharmacological interventions to reduce levels of stress, anxiety or depression in women who have had miscarriage, those were excluded from the systematic review because women were not pregnant at the time of the study or because miscarriage was analysed as a composite variable including other types of perinatal loss such a stillbirth or neonatal death (table 1). Furthermore, even though it was part of our initial objectives, this review did not find evidence of any RCTs that measured biomarkers of stress, such as cortisol, to assess the effect of psychological interventions in this population. As a consequence, no results were included in this systematic review.

Although none of the remaining RCTs met the full inclusion criteria $(n=7)$ (see table 1$)$, they have useful information for health professionals who are working in the area of pregnancy loss. In summary, only one RCT studied women while they were pregnant, ${ }^{62}$ but miscarriage was analysed as a composite variable with perinatal neonatal death. More than half of the RCTs identified were pilot or feasibility studies ${ }^{62-65}$ and had a small sample size with low statistical power. The most frequently measured outcomes were depression, anxiety, stress and grief (see online supplementary file 5). Levels of perceived stress were measured by four RCTs. ${ }^{63-66}$ Results of the RCTs varied, with some suggesting a positive reduction in levels of stress and depression when women took part in psychological interventions compared with a control group (see online supplementary file 4). Other studies found no change or did not reach statistically significant results on psychological outcomes (see online supplementary file 4). Supporting files describing main characteristics, outcome matrix and risk of bias of those relevant seven RCTs can be found online (see online supplementary files 4, 5 and 6 ). These supportive materials might help clinicians, researchers and decision-makers to increase the awareness of the available supportive interventions in the area of pregnancy loss as well as the lack of evidence or methodological quality in these types of studies.

\section{DISCUSSION}

The aim of this review was to systematically assess the effect of non-pharmacological interventions to reduce levels of stress in pregnant women who have had a miscarriage in their previous pregnancy. Unfortunately, no RCT met our inclusion criteria. The results of this review were unexpected given that first, several studies have previously reported the psychological impact on pregnant women with a history of miscarriage $e^{436768}$ and second, because relevant institutions and organisations in the area of clinical health practice have reported the need of good-quality, adequately powered RCTs to evaluate interventions aimed at tackling moderate to severe psychological disorders in the pregnant population. ${ }^{6} 69$

\section{Comparison with other studies}

There is an agreement in the literature that women who miscarry may suffer from psychological morbidities after pregnancy loss and in a subsequent pregnancy ${ }^{70-72}$ However, there are important limitations when summarising this evidence such as a lack of a comparison 


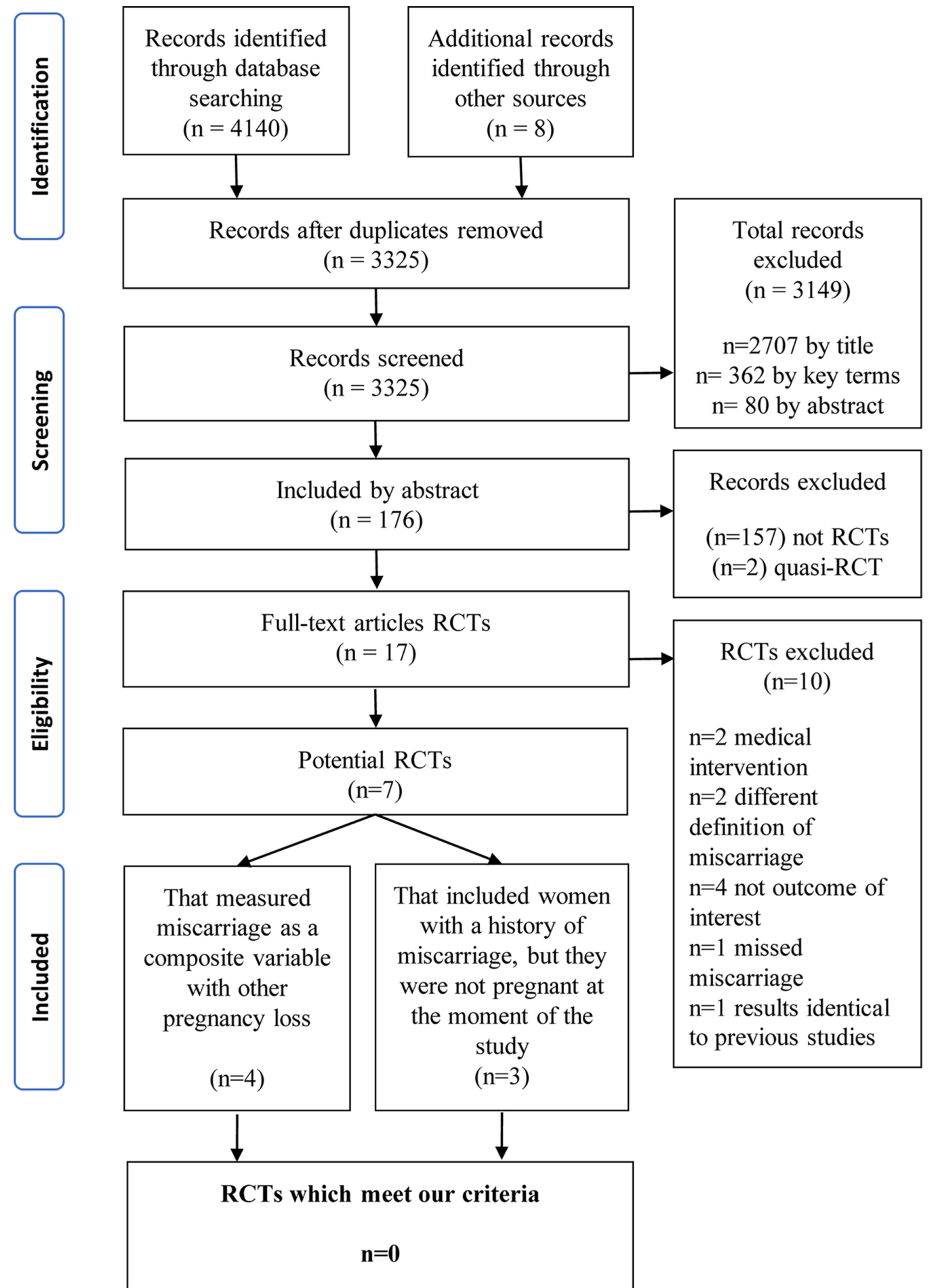

Figure 1 Flow diagram of the selection of the studies. RCTs, randomised controlled trials.

group within these studies or the overlapping of depression and anxiety symptoms and disorders. ${ }^{22}$ Furthermore, levels of stress were not assessed in women following miscarriage or in subsequent pregnancy in any of the reviews identified. ${ }^{25} 7172$

According to the most recent Cochrane systematic review, which assessed the effectiveness of non-pharmacological interventions on women with a history of miscarriage, only six randomised controlled studies assessed the effect of psychological well-being interventions in women who experienced miscarriage. ${ }^{73}$ None of them were carried out in women who were pregnant at the time of the study. These studies were also limited by a lack of power, unclear blinding or no blinding, heterogeneity between types of psychological follow-up and small sample size. Murphy et al (2012) concluded that not enough evidence was achieved to state if psychological interventions were beneficial for women who miscarry. ${ }^{73}$ 


\section{Limitations of the study}

As with other type of studies, this review is not free of limitations. First, only one RCT included pregnant women despite previous pilot RCTs assessing non-pharmacological interventions to reduce levels of stress, anxiety and depression had included pregnant women as their target population. ${ }^{74-76}$ Historically, pregnant women have been excluded from clinical research due to potential ethical considerations such as (1) they are classified as a vulnerable group, (2) the possible risk of harming the fetus or (3) the complicated physiology during pregnancy. ${ }^{77}$

Several efforts have been made to encourage researchers and clinicians to challenge these limitations and to include pregnant women in clinical research. ${ }^{78}$ The basic principles in ethical foundation for including pregnant women in clinical research are: (1) the need for evidence-based knowledge of effective treatments during pregnancy; (2) the uncertain risk of not treating or undertreating a mother's condition and (3) the ethical justification of the possible benefits of participating in research. ${ }^{78}$ As Macklin (2010) stated 'the next logical-and ethical-step is the enrolment and retention of pregnant women in clinical trials' ${ }^{79}$
Another limitation identified when undertaking this review was the different definitions of miscarriage found in the literature during the selection process. Definitions of miscarriage vary significantly between countries, professional bodies and clinical guidelines. ${ }^{80}$ This variety of definitions made it difficult to compare and to evaluate the evidence between different countries in this field. ${ }^{80}$

As important as the lack of an international concordance between definitions, this review found that some RCTs pooled together the results from miscarriage with other types of perinatal death such as stillbirth or neonatal death. One of the possible limitations is that, as per protocol, interventions carried out among women with recurrent miscarriage and/or perinatal death, or as a composite variables, were excluded in the screening process. It is reported that pregnancy loss and perinatal death have shown different psychological reactions to the loss. ${ }^{81-83}$ Moreover, the impact that a specific intervention might have on psychological well-being may differ as women are managed differently in a subsequent pregnancy depending on the type of pregnancy loss they have experienced. ${ }^{84} 85$ For instance, more resources are invested in women with recurrent miscarriage, ${ }^{86}$

Table 1 List of all RCTs and CCTs $(n=19)$ and reason for exclusion

\begin{tabular}{|c|c|c|c|c|}
\hline & \multirow[b]{2}{*}{ Authors, year } & \multicolumn{2}{|c|}{ Pregnant $^{*}$} & \multirow{2}{*}{$\begin{array}{l}\text { All RCTs and CCTs studies } \\
\text { Reason for exclusion }\end{array}$} \\
\hline & & Yes & No & \\
\hline \multicolumn{5}{|c|}{ CCTs $(n=2)$} \\
\hline 1. & Klein et al, $2012^{97}$ & & $\checkmark$ & Partially randomised patient design \\
\hline 2. & Séjourné et al, $2011^{98}$ & & $\checkmark$ & Quasi-RCT \\
\hline \multicolumn{5}{|c|}{ RCTs $(n=10)$} \\
\hline 3. & Adolfsson et al, $2006^{99}$ & & $\checkmark$ & No outcome of interest included \\
\hline 4. & Huffman, $2015^{100}$ & & $\checkmark$ & No outcome of interest included \\
\hline 5. & Lok, $2006^{70}$ & & $\checkmark$ & Results are identical than Kong, 2014 \\
\hline 6. & Klinitzke et al, 2013 101 & & $\checkmark$ & No outcome of interest included \\
\hline 7. & Kong et al, $2013^{102}$ & & $\checkmark$ & Medical intervention \\
\hline 8. & Lee et al, $2001^{103}$ & & $\checkmark$ & Medical intervention \\
\hline 9. & Neugebauer et al, $2007^{104}$ & & $\checkmark$ & Pregnancy loss later than 24 weeks \\
\hline 10. & Neugebauer et al, 2006 ${ }^{105}$ & & $\checkmark$ & Pregnancy loss later than 24 weeks \\
\hline 11. & Nikcević et al, $2007^{106}$ & & $\checkmark$ & Missed miscarriage \\
\hline 12. & Swanson, $1999^{27}$ & & $\checkmark$ & No outcome of interest included \\
\hline \multicolumn{5}{|c|}{$\operatorname{RCTs}(n=7)$} \\
\hline 13. & Côté-Arsenault et al, $2014^{62}$ & $\checkmark$ & & Pregnancy loss as a composite variable \\
\hline 14. & Johnson et al, $2016^{63}$ & & $\checkmark$ & Pregnancy loss as a composite variable \\
\hline 15. & Kersting et al, $2013^{66}$ & & $\checkmark$ & Pregnancy loss as a composite variable \\
\hline 16. & Kersting et al, $2011^{65}$ & & $\checkmark$ & Pregnancy loss as a composite variable \\
\hline 17. & Kong et al, $2014^{107}$ & & $\checkmark$ & Not pregnant at the time of the study \\
\hline 18. & Lee et al, $1996^{64}$ & & $\checkmark$ & Not pregnant at the time of the study \\
\hline 19. & Swanson et al, $2009^{28}$ & & $\checkmark$ & Not pregnant at the time of the study \\
\hline
\end{tabular}

${ }^{*}$ Subsequent pregnancy after miscarriage. Not including pregnancy which resulted in miscarriage.

CCTs, clinical controlled trials; RCTs, randomised controlled trials. 
and supportive care is regularly offered to women with unexplained recurrent miscarriage. ${ }^{48-89}$ Consequently, reporting composite results might mislead the evidence in this research area.

Studies also illustrate that there are no differences between gestational age at pregnancy loss and adverse psychological outcomes. ${ }^{37} 90$ 91 Hutti et al (2015) found no statistically significant differences between type of loss and grief, anxiety, depression or post-traumatic stress disorders among women in their subsequent healthy pregnancy. ${ }^{92}$ In addition, greater grief intensity was associated with increased pregnancy-specific anxiety, depression symptoms and PTSD. As a result, alternative approaches suggest to evaluate psychological outcomes in subsequent healthy pregnancies after a loss such as adopting the theoretical framework of perinatal grief intensity. ${ }^{93} 94$

\section{Implications and conclusion}

It is commonly perceived that empty reviews, that is, systematic reviews that find no studies eligible for inclusion, do not provide additional information that can be used by clinicians and other decision-makers. ${ }^{95}$ However, some authors argue that empty reviews can be of critical importance (1) to raise awareness of the gaps in the evidence in a particular area of interest for either clinicians, researchers and decision-makers, (2) to know who is interested in the area and (3) to indicate the state of research evidence at a particular point in time. ${ }^{95} 96$ In particular, this review is clinically important because it might help encourage the development and implementation of well-designed clinical trials for assessing non-pharmacological interventions on pregnant women who have had miscarriage.

In conclusion, it is accepted that miscarriage affects some women's psychological well-being, increasing their levels of stress after a single experience. It is also considered that previous miscarriage may be a factor in aggravating levels of stress in a subsequent pregnancy. There is a potential risk that women who have experienced miscarriage may be at risk for maternal stress during their subsequent pregnancy which in turn is associated with adverse pregnancy-related outcomes. To date, few studies have assessed the effect of non-medical interventions in women after pregnancy loss. Moreover, none of the RCTs, which were identified in this review, included pregnant women in their subsequent pregnancy after miscarriage. Therefore, there is a need for targeted, standardised, high-quality and powered RCTs that can provide reliable and conclusive results to determine effective psychological and support interventions for this vulnerable group.

Contributors KOD and SM conceived the study. KOD, SM and ISLC participated in its design. ISLC and KM independently screened and selected the studies. KOD and SM resolved discrepancies when they arose in the selection of the studies. ISLC completed the data extraction forms for the selected studies and SM independently checked the content. All authors helped draft the manuscript. All authors read and approved the final manuscript. KOD is the lead author.

Funding None.

Competing interests None declared.
Provenance and peer review Not commissioned; externally peer reviewed.

Data sharing statement The ENDNOTE library and the excel sheet to collect studies included in data repository websites used in the search strategy are available from the corresponding author on reasonable request.

Open Access This is an Open Access article distributed in accordance with the Creative Commons Attribution Non Commercial (CC BY-NC 4.0) license, which permits others to distribute, remix, adapt, build upon this work non-commercially, and license their derivative works on different terms, provided the original work is properly cited and the use is non-commercial. See: http://creativecommons.org/ licenses/by-nc/4.0/

(c) Article author(s) (or their employer(s) unless otherwise stated in the text of the article) 2017. All rights reserved. No commercial use is permitted unless otherwise expressly granted.

\section{REFERENCES}

1. Dole N, Savitz DA, Hertz-Picciotto I, et al. Maternal stress and preterm birth. Am J Epidemiol 2003;157:14-24.

2. Woods SM, Melville JL, Guo Y, et al. Psychosocial stress during pregnancy. Am J Obstet Gynecol 2010;202:61 e1-7.

3. Vollebregt KC, van der Wal MF, Wolf $\mathrm{H}$, et al. Is psychosocial stress in first ongoing pregnancies associated with pre-eclampsia and gestational hypertension? BJOG 2008;115:607-15.

4. Maconochie N, Doyle P, Prior S, et al. Risk factors for first trimester miscarriage--results from a UK-population-based case-control study. BJOG 2007;114:170-86.

5. Yali AM, Lobel M. Coping and distress in pregnancy: an investigation of medically high risk women. J Psychosom Obstet Gynaecol 1999;20:39-52.

6. National Institute for Health and Care Excellence. Antenatal and postnatal mental health: clinical management and service guidance: National Institute for Health and Care Excellence; 2014. http://www. nice.org.uk/guidance/cg192 (accessed 5 Nov 2016).

7. Lobel M, Cannella DL, Graham JE, et al. Pregnancy-specific stress, prenatal health behaviors, and birth outcomes. Health Psychol 2008;27:604-15.

8. Wadhwa PD, Entringer S, Buss C, et al. The contribution of maternal stress to preterm birth: issues and considerations. Clin Perinatol 2011;38:351-84.

9. Cole-Lewis HJ, Kershaw TS, Earnshaw VA, et al. Pregnancyspecific stress, preterm birth, and gestational age among high-risk young women. Health Psychol 2014;33:1033-45.

10. Wadhwa PD, Culhane JF, Rauh V, et al. Stress and preterm birth: neuroendocrine, immune/inflammatory, and vascular mechanisms. Matern Child Health J 2001;5:119-25.

11. Qu XL, Zhu WJ, Chen WQ, et al. Effect of pregnancy-specific stress on spontaneous preterm birth among Chinese people. Clin Exp Obstet Gynecol 2016;43:103-8.

12. Dipietro JA. Maternal stress in pregnancy: considerations for fetal development. J Adolesc Health 2012;51(2 Suppl):S3-8.

13. Alder J, Fink N, Bitzer J, et al. Depression and anxiety during pregnancy: a risk factor for obstetric, fetal and neonatal outcome? A critical review of the literature. J Matern Fetal Neonatal Med 2007;20:189-209.

14. Poulose T, Richardson R, et al. Ewings PProbability of early pregnancy loss in women with vaginal bleeding and a singleton live fetus at ultrasound scan. J Obstet Gynaecol 2006;26:782-4.

15. Early pregnancy loss. Practice bulletin no. 150: American College of Obstetricians and Gynecologists. 2015.

16. Zinaman MJ, Clegg ED, Brown CC, et al. Estimates of human fertility and pregnancy loss. Fertil Steril 1996;65:503-9.

17. Wilcox AJ, Weinberg CR, O'Connor JF, et al. Incidence of early loss of pregnancy. N Engl J Med 1988;319:189-94.

18. Hure AJ, Powers JR, Mishra GD, et al. Miscarriage, preterm delivery, and stillbirth: large variations in rates within a cohort of Australian women. PLoS One 2012;7:e37109.

19. Frost M, Condon JT. The psychological sequelae of miscarriage: a critical review of the literature. Aust N Z J Psychiatry 1996;30:54-62.

20. Toffol E, Koponen P, Partonen T. Miscarriage and mental health: results of two population-based studies. Psychiatry Res 2013;205(1-2):151-8.

21. World Health Organization. Mental health aspects of women's reproductive health: a global review of the literature: World Health Organization,. 2009.

22. Geller PA, Kerns D, Klier CM. Anxiety following miscarriage and the subsequent pregnancy. J Psychosom Res 2004;56:35-45. 
23. Cumming GP, Klein S, Bolsover D, et al. The emotional burden of miscarriage for women and their partners: trajectories of anxiety and depression over 13 months. BJOG 2007;114:1138-45.

24. Nikcevic AV, Tunkel SA, Kuczmierczyk AR, et al. Investigation of the cause of miscarriage and its influence on women's psychological distress. Br J Obstet Gynaecol 1999;106:808-13.

25. Lok IH, Neugebauer R. Psychological morbidity following miscarriage. Best Pract Res Clin Obstet Gynaecol 2007;21:229-47.

26. Lok IH, Yip AS-K, Lee DT-S, et al. A 1-year longitudinal study of psychological morbidity after miscarriage. Fertil Steril 2010;93:1966-75.

27. Swanson KM. Effects of caring, measurement, and time on miscarriage impact and women's well-being. Nurs Res 1999;48:288-98.

28. Swanson KM, Chen HT, Graham JC, et al. Resolution of depression and grief during the first year after miscarriage: a randomized controlled clinical trial of couples-focused interventions. J Womens Health 2009;18:1245-57.

29. Brier N. Anxiety after miscarriage: a review of the empirical literature and implications for clinical practice. Birth 2004;31:138-42.

30. Cecil R, Leslie J. Early miscarriage: preliminary results from a study in Northern Ireland. J Reprod Infant Psychol 1993;11:89-95.

31. Cordle CP RJ. A 2-year follow-up of women who have experienced early miscarriage. J Reprod Infant Psychol 1994;12:37-43.

32. Janssen HJ, Cuisinier MC, Hoogduin KA, et al. Controlled prospective study on the mental health of women following pregnancy loss. Am J Psychiatry 1996;153:226-30.

33. Neugebauer R, Kline J, Shrout P, et al. Major depressive disorder in the 6 months after miscarriage. JAMA 1997:277:383-8.

34. Bergner A, Beyer R, Klapp BF, et al. Pregnancy after early pregnancy loss: a prospective study of anxiety, depressive symptomatology and coping. J Psychosom Obstet Gynaecol 2008;29:105-13.

35. Hutti MH, Armstrong DS, Myers J. Healthcare utilization in the pregnancy following a perinatal loss. MCN Am J Matern Child Nurs 2011;36:104-11.

36. Gaudet C, Séjourné N, Camborieux L, et al. Pregnancy after perinatal loss: association of grief, anxiety and attachment. $J$ Reprod Infant Psychol 2010;28:240-51.

37. Woods-Giscombé CL, Lobel M, Crandell JL. The impact of miscarriage and parity on patterns of maternal distress in pregnancy. Res Nurs Health 2010;33:316-28.

38. Armstrong DS. Emotional distress and prenatal attachment in pregnancy after perinatal loss. J Nurs Scholarsh 2002;34:339-45.

39. Côté-Arsenault D, Donato KL, Earl SS. Watching \& worrying: early pregnancy after loss experiences. MCN Am J Matern Child Nurs 2006;31:356-63.

40. McCarthy FP, Moss-Morris R, Khashan AS, et al. Previous pregnancy loss has an adverse impact on distress and behaviour in subsequent pregnancy. BJOG 2015;122:1757-64.

41. Côté-Arsenault $D$. Threat appraisal, coping, and emotions across pregnancy subsequent to perinatal loss. Nurs Res 2007;56:108-16.

42. Armstrong DS. Impact of prior perinatal loss on subsequent pregnancies. J Obstet Gynecol Neonatal Nurs 2004;33:765-73.

43. Armstrong D, Hutti M. Pregnancy after perinatal loss: the relationship between anxiety and prenatal attachment. $J$ Obstet Gynecol Neonatal Nurs 1998;27:183-9.

44. Gong X, Hao J, Tao F, et al. Pregnancy loss and anxiety and depression during subsequent pregnancies: data from the C-ABC study. Eur J Obstet Gynecol Reprod Biol 2013;166:30-6.

45. Bicking Kinsey C, Baptiste-Roberts K, Zhu J, et al. Effect of previous miscarriage on depressive symptoms during subsequent pregnancy and postpartum in the first baby study. Matern Child Health J 2015;19:391-400.

46. Clifford K, Rai R, Regan L. Future pregnancy outcome in unexplained recurrent first trimester miscarriage. Hum Reprod 1997:12:387-9.

47. Liddell HS, Pattison NS, Zanderigo A. Recurrent miscarriage-outcome after supportive care in early pregnancy. Aust N Z J Obstet Gynaecol 1991;31:320-2.

48. Stray-Pedersen B, Stray-Pedersen S. Etiologic factors and subsequent reproductive performance in 195 couples with a prior history of habitual abortion. Am J Obstet Gynecol 1984:148:140-6.

49. Jauniaux E, Farquharson RG, Christiansen OB, et al. Evidencebased guidelines for the investigation and medical treatment of recurrent miscarriage. Hum Reprod 2006;21:2216-22.

50. Farren J, Jalmbrant M, Ameye L, et al. Post-traumatic stress, anxiety and depression following miscarriage or ectopic pregnancy: a prospective cohort study. BMJ Open 2016;6:e011864.
51. Higgins JPT, Green S, Cochrane Collaboration. Cochrane handbook for systematic reviews of interventions. Chichester, England; Hoboken, NJ: Wiley-Blackwell, 2008.

52. Ryan R. Cochrane consumers and communication review group: Data synthesis and analysis. Cochrane Consum Commun Rev Gr 2013.

53. Moher D, Liberati A, Tetzlaff J, et al. Preferred reporting items for systematic reviews and meta-analyses: the PRISMA statement. BMJ 2009;339:b2535.

54. Health Service Executive. Ultrasound diagnosis of early pregnancy miscarriage. Clinical practice guideline 2010.

55. Gellman MD, Turner JR. Encyclopedia of behavioral medicine. New York: Springer, 2013.

56. American Psychiatric Association. Diagnostic criteria from DSM-IVTR. Washington, DC: American Psychiatric Association, 2000.

57. Higgins J, Green S. Cochrane handbook for systematic reviews of interventions. Wiley-Blackwell: Oxford, 2008.

58. Jeve YB, Davies W. Evidence-based management of recurrent miscarriages. J Hum Reprod Sci 2014;7:159-69.

59. Ford HB, Schust DJ. Recurrent pregnancy loss: etiology, diagnosis, and therapy. Rev Obstet Gynecol 2009;2:76-83.

60. Dwan K, Gamble C, Kolamunnage-Dona R, et al. Assessing the potential for outcome reporting bias in a review: a tutorial. Trials 2010;11:52.

61. The Cochrane Collaboration. Cochrane consumers and communication review group: The Cochrane Collaboration;. 2013 http://cccrg.cochrane.org/author-resources (accessed Feb 2016).

62. Côté-Arsenault D, Schwartz K, Krowchuk H, et al. Evidence-based intervention with women pregnant after perinatal loss. MCN Am J Matern Child Nurs 2014;39:177-86.

63. Johnson JE, Price AB, Kao JC, et al. Interpersonal psychotherapy (IPT) for major depression following perinatal loss: a pilot randomized controlled trial. Arch Womens Ment Health 2016;19.

64. Lee C, Slade P, Lygo V. The influence of psychological debriefing on emotional adaptation in women following early miscarriage: a preliminary study. Br J Med Psychol 1996;69:47-58.

65. Kersting A, Kroker K, Schlicht S, et al. Efficacy of cognitive behavioral internet-based therapy in parents after the loss of a child during pregnancy: pilot data from a randomized controlled trial. Arch Womens Ment Health 2011;14:465-77.

66. Kersting A, Dölemeyer R, Steinig J, et al. Brief Internet-based intervention reduces posttraumatic stress and prolonged grief in parents after the loss of a child during pregnancy: a randomized controlled trial. Psychother Psychosom 2013;82:372-81.

67. Theut SK, Pedersen FA, Zaslow MJ, et al. Pregnancy subsequent to perinatal loss: parental anxiety and depression. J Am Acad Child Adolesc Psychiatry 1988;27:289-92.

68. Franche RL, Mikail SF. The impact of perinatal loss on adjustment to subsequent pregnancy. Soc Sci Med 1999;48:1613-23.

69. Mehta M, Pattanayak R. Follow-up for improving psycholgoical well-being for women after a miscarriage: Rhl commentary. Geneva: The WHO Reproductive Health Library, 2013. http://apps. who. int/rhl/pregnancy_childbirth/antenatal_care/general/cd008679_ mehtam com/en/.

70. Lok IH. Psychological morbidity after miscarriage [Doctor of Medicine]. The Chinese University of Hong Kong, 2006.

71. Klier CM, Geller PA, Ritsher JB. Affective disorders in the aftermath of miscarriage: a comprehensive review. Arch Womens Ment Health 2002;5:129-49.

72. Geller PA, Kerns D, Klier CM. Anxiety following miscarriage and the subsequent pregnancy: a review of the literature and future directions. J Psychosom Res 2004;56:35-45.

73. Murphy FA, Lipp A, Powles DL. Follow-up for improving psychological well being for women after a miscarriage. Cochrane Database Syst Rev 2012;3:Cd008679.

74. Woolhouse H, Mercuri K, Judd F, et al. Antenatal mindfulness intervention to reduce depression, anxiety and stress: a pilot randomised controlled trial of the MindBabyBody program in an Australian tertiary maternity hospital. BMC Pregnancy Childbirth 2014;14:369.

75. Guardino CM, Dunkel Schetter C, Bower JE, et al. Randomised controlled pilot trial of mindfulness training for stress reduction during pregnancy. Psychol Health 2014;29:334-49.

76. Vieten C, Astin J. Effects of a mindfulness-based intervention during pregnancy on prenatal stress and mood: results of a pilot study. Arch Womens Ment Health 2008;11:67-74.

77. Blehar MC, Spong C, Grady C, et al. Enrolling pregnant women: issues in clinical research. Womens Health Issues 2013;23:e39-45.

78. Lyerly AD, Little MO, Faden R. The second wave: toward responsible inclusion of pregnant women in research. Int $\mathrm{J}$ Fem Approaches Bioeth 2008;1:5-22. 
79. Macklin R. Enrolling pregnant women in biomedical research. Lancet 2010;375:632-3.

80. Wright PM. Barriers to a comprehensive understanding of pregnancy loss. J Loss Trauma 2011:16:1-12.

81. Theut SK, Zaslow MJ, Rabinovich BA, et al. Resolution of parental bereavement after a perinatal loss. J Am Acad Child Adolesc Psychiatry 1990;29:521-5.

82. Goldbach KR, Dunn DS, Toedter LJ, et al. The effects of gestational age and gender on grief after pregnancy loss. Am J Orthopsychiatry 1991;61:461-7.

83. Cuisinier MC, Kuijpers JC, Hoogduin CA, et al. Miscarriage and stillbirth: time since the loss, grief intensity and satisfaction with care. Eur J Obstet Gynecol Reprod Biol 1993;52:163-8.

84. Health Service Executive. National standards for bereavement care following pregnancy loss and perinatal death. Republic of Ireland: Health Service Executive, 2016.

85. Stillbirth \& neonatal death charity. Bereavement care report 2010. Survey of UK maternity units and the care they provide to parents whose baby dies before, during or shortly after birth. UK: Sands, 2010.

86. Meaney S, Corcoran P, Spillane N, et al. Experience of miscarriage: an interpretative phenomenological analysis. BMJ Open 2017;7: 011382.

87. Musters AM, Taminiau-Bloem EF, van den Boogaard E, et al. Supportive care for women with unexplained recurrent miscarriage: patients' perspectives. Hum Reprod 2011;26:873-7.

88. Musters AM, Koot YE, van den Boogaard NM, et al. Supportive care for women with recurrent miscarriage: a survey to quantify women's preferences. Hum Reprod 2013;28:398-405.

89. Bailey S, Bailey C, Boivin J, et al. A feasibility study for a randomised controlled trial of the Positive Reappraisal Coping Intervention, a novel supportive technique for recurrent miscarriage. BMJ Open 2015;5:e007322.

90. Lamb EH. The impact of previous perinatal loss on subsequent pregnancy and parenting. J Perinat Educ 2002;11:33-40.

91. Thapar AK, Thapar A. Psychological sequelae of miscarriage: a controlled study using the general health questionnaire and the hospital anxiety and depression scale. Br J Gen Pract 1992;42:94-6.

92. Hutti MH, Armstrong DS, Myers JA, et al. Grief intensity, psychological well-being, and the intimate partner relationship in the subsequent pregnancy after a perinatal loss. J Obstet Gynecol Neonatal Nurs 2015;44:42-50.

93. Hutti MH, Armstrong DS, Myers J. Evaluation of the perinatal grief intensity scale in the subsequent pregnancy after perinatal loss. $J$ Obstet Gynecol Neonatal Nurs 2013;42:697-706.
94. Côté-Arsenault D, Dombeck MT. Maternal assignment of fetal personhood to a previous pregnancy loss: relationship to anxiety in the current pregnancy. Health Care Women Int 2001;22:649-65.

95. Yaffe J, Montgomery P, Hopewell S, et al. Empty reviews: a description and consideration of Cochrane systematic reviews with no included studies. PLoS One 2012;7:e36626.

96. Lang A, Edwards N, Fleiszer A. Empty systematic reviews: hidden perils and lessons learned. J Clin Epidemiol 2007;60:595-7.

97. Klein S, Cumming GP, Lee AJ, et al. Evaluating the effectiveness of a web-based intervention to promote mental wellbeing in women and partners following miscarriage, using a modified patient preference trial design: an external pilot. BJOG 2012;119:762-7.

98. Séjourné N, Callahan S, Chabrol H. [The efficiency of a brief support intervention for anxiety, depression and stress after miscarriage]. $J$ Gynecol Obstet Biol Reprod 2011;40:437-43.

99. Adolfsson A, Berterö C, Larsson PG. Effect of a structured follow-up visit to a midwife on women with early miscarriage: a randomized study. Acta Obstet Gynecol Scand 2006;85:330-5.

100. Huffman CS. The meaning of miscarriage: Measurement, reproductive factors and trajectories in couple dyads Doctor in Philosophy. The University of North Carolina at Chapel Hill, 2015.

101. Klinitzke G, Doelemeyer R, Steinig J, et al. Internet-based therapy after pregnancy loss - the impact of social support on bereavement. Verhaltenstherapie 2013;23:181-8.

102. Kong GW, Lok IH, Yiu AK, et al. Clinical and psychological impact after surgical, medical or expectant management of first-trimester miscarriage--a randomised controlled trial. Aust N Z J Obstet Gynaecol 2013;53:170-7.

103. Lee DT, Cheung LP, Haines CJ, et al. A comparison of the psychologic impact and client satisfaction of surgical treatment with medical treatment of spontaneous abortion: a randomized controlled trial. Am J Obstet Gynecol 2001;185:953-8.

104. Neugebauer R, Kline J, Bleiberg K, et al. Preliminary open trial of interpersonal counseling for subsyndromal depression following miscarriage. Depress Anxiety 2007;24:219-22.

105. Neugebauer R, Kline J, Markowitz JC, et al. Pilot randomized controlled trial of interpersonal counseling for subsyndromal depression following miscarriage. J Clin Psychiatry 2006;67:1299-304.

106. Nikcević AV, Kuczmierczyk AR, Nicolaides KH. The influence of medical and psychological interventions on women's distress after miscarriage. J Psychosom Res 2007;63:283-90.

107. Kong GW, Chung TK, Lok IH. The impact of supportive counselling on women's psychological wellbeing after miscarriage--a randomised controlled trial. BJOG 2014;121:1253-62. 